\title{
The safety and efficacy of use of low-molecular-weight heparin in pediatric neurosurgical patients
}

\author{
David D. Gonda, MD, Jared Fridley, MD, Sheila L. Ryan, MPH, JD, Valentina Briceño, RN, \\ Sandi K. Lam, MD, MBA, Thomas G. Luerssen, MD, and Andrew Jea, MD \\ Division of Pediatric Neurosurgery, Texas Children's Hospital, and Department of Neurosurgery, Baylor College of Medicine, \\ Houston, Texas
}

\begin{abstract}
OBJECT Low-molecular-weight heparins (LMWHs), mainly enoxaparin, offer several advantages over standard anticoagulation therapies such as unfractionated heparin and warfarin, including predictable pharmacokinetics, minimal monitoring, and subcutaneous administration. The purpose of this study was to determine the safety and efficacy of LMWHs in pediatric neurosurgical patients.
\end{abstract}

METHODS A retrospective study was performed with patients 18 years old or younger who were admitted to the Pediatric Neurosurgery Service at Texas Children's Hospital and treated with LMWH for either therapeutic or prophylactic purposes between March 1, 2011, and December 30, 2013. Demographic and clinical features and outcomes were recorded.

RESULTS LMWH was administered for treatment of venous thromboembolic events (VTEs) in 17 children and for prophylaxis in 24 children. Clinical resolution of VTEs occurred in 100\% (17 of 17) of patients receiving therapeutic doses of LMWH. No patient receiving prophylactic doses of LMWH developed a new VTE. Major or minor bleeding complications occurred in 18\% (3 of 17 children) and $4 \%$ (1 of 24 children) of those receiving therapeutic and prophylactic doses, respectively. All 4 patients who experienced hemorrhagic complications had other bleeding risk factors-i.e., coagulopathies and antiplatelet medications.

CONCLUSIONS LMWH seems to be safe and efficacious for both management and prophylaxis of VTEs in pediatric neurosurgery. However, pediatric practitioners should be aware of higher risk for bleeding complications with increasing doses of LMWH, especially in patients with preexisting bleeding disorders or concurrent use of antiplatelet agents.

http://thejns.org/doi/abs/10.3171/2015.1.PEDS14489

KEY WORDS low-molecular-weight heparin; enoxaparin; venous thromboembolism; deep venous thrombosis; anticoagulation; pediatric neurosurgery; hemorrhage; vascular disorders

$\mathrm{P}$ EDIATRIC venous thromboembolic events (VTEs) have become an emerging problem in Canada, with a 10 -fold increase in incidence over the original estimates since the early 1990s, especially in tertiary care hospitals. ${ }^{1}$ Plausible explanations for the rise in this population are related advances in tertiary pediatric health care that result in improved survival of critically ill children. ${ }^{1} \mathrm{~A}$ more significant contributor is the increased use of central venous catheters in these children. ${ }^{13}$ VTE complications have been shown to independently increase inpatient costs and length of stay in young trauma patients. ${ }^{4,8}$

Current therapy for management of VTEs in children is extrapolated from clinical experience and trials with adult patients. It usually consists of therapy with unfractionat- ed heparin, low-molecular-weight heparin (LMWH), oral anticoagulants, or a combination of these medications. ${ }^{1,10}$ Poor venous access, unpredictable pharmacokinetics requiring serial monitoring, increased risk of bleeding related to primary disorders, and the influence of disease, diet, or medications adversely influence the safe usage of unfractionated heparin and oral anticoagulants, particularly in younger patients. $5,6,10,16,19,20$

LMWHs offer several advantages over unfractionated heparin and oral anticoagulants in the management and prevention of VTEs in children, ${ }^{14}$ including predictable pharmacokinetics, subcutaneous administration, and minimal monitoring. However, there have been few studies in children assessing the pharmacokinetics, safety, and effi-

ABBREVIATIONS LMWH = low-molecular-weight heparin; VTE = venous thromboembolic event.

SUBMITTED September 16, 2014. ACCEPTED January 22, 2015.

INCLUDE WHEN CITING Published online June 12, 2015; DOI: 10.3171/2015.1.PEDS14489.

DISCLOSURE The authors report no conflict of interest concerning the materials or methods used in this study or the findings specified in this paper. 
TABLE 1. Children receiving prophylactic LMWH

\begin{tabular}{|c|c|c|c|c|}
\hline $\begin{array}{c}\text { Sex/Age } \\
\text { (yrs) }\end{array}$ & Condition & Operation & $\begin{array}{l}\text { Other Bleeding } \\
\text { Risk }\end{array}$ & $\begin{array}{l}\text { Type of Major } \\
\text { Hemorrhage }\end{array}$ \\
\hline $\mathrm{F} / 15$ & Lumbar stenosis & L1-2 laminectomies & & \\
\hline $\mathrm{M} / 17$ & Traumatic cervical spinal cord injury (C-5) & C4-6 instrumented fusion & & \\
\hline $\mathrm{F} / 14$ & Traumatic cervical spinal cord injury (C-4) & C4-T3 instrumented fusion & Aspirin & \\
\hline$M / 15$ & Thalamic tumor & Craniotomy, tumor resection & Hemophilia & Intracerebral \\
\hline$M / 16$ & Rasmussen disease & Craniotomy, functional hemispherectomy & & \\
\hline $\mathrm{F} / 16$ & AVM & Craniotomy, AVM resection & & \\
\hline$M / 12$ & Ewing sarcoma of spine & T2-4 laminoplasty, tumor resection & & \\
\hline $\mathrm{F} / 18$ & Lumbar stenosis & L3-S1 laminectomies & & \\
\hline $\mathrm{F} / 10$ & Lumbar spondylolisthesis & L5-S1 instrumented fusion & & \\
\hline$M / 16$ & Traumatic lumbar spine injury & T11-L2 instrumented fusion & & \\
\hline$M / 13$ & Lumbar epidural abscess & L4-S1 laminectomies & & \\
\hline $\mathrm{F} / 13$ & Skull defect, remote head injury & Cranioplasty & & \\
\hline $\mathrm{F} / 14$ & Neuromuscular scoliosis & T3-ilium fusion & & \\
\hline $\mathrm{F} / 6$ & Intractable epilepsy & Functional hemispherotomy & & \\
\hline $\mathrm{F} / 15$ & Medulloblastoma & Craniotomy for tumor & & \\
\hline$M / 15$ & $\mathrm{~L}-1$ burst fracture & T10-L3 posterior fusion & & \\
\hline$M / 3$ & Epilepsy & Functional hemispherotomy & & \\
\hline $\mathrm{M} / 17$ & Lumbar stenosis & L2-S1 laminectomy & & \\
\hline$M / 16$ & Basal ganglia glioma & Craniotomy for tumor & & \\
\hline $\mathrm{M} / 12$ & L5-S1 spondylolysis & L5-S1 posterior fusion & & \\
\hline$M / 16$ & C-3 osteoblastoma, myelopathy & C2-4 posterior fusion, tumor resection & & \\
\hline $\mathrm{F} / 12$ & Midbrain pilocytic astrocytoma & Craniotomy for tumor & & \\
\hline $\mathrm{M} / 17$ & Postlaminectomy kyphosis & C5-L3 posterior fusion & & \\
\hline $\mathrm{M} / 14$ & Gunshot wound to head & Craniotomy for foreign object & & \\
\hline
\end{tabular}

$\mathrm{AVM}=$ arteriovenous malformation.

cacy of LMWH. ${ }^{10,21}$ Furthermore, to the best of our knowledge, there have been no studies analyzing the safety and efficacy of LMWH in pediatric neurosurgical patients. ${ }^{11}$

\section{Methods}

\section{Patient Population}

Institutional review board approval was obtained for this study from the Baylor College of Medicine. We retrospectively reviewed data on 2296 children operated on by the Pediatric Neurosurgery Service at Texas Children's Hospital between March 1, 2011, and December 30, 2013, and screened for those who were treated with the LMWH enoxaparin. Dosing alterations for therapy were made according to a published nomogram to maintain the antifactor Xa level between 0.5 and $1.0 \mathrm{U} / \mathrm{ml}$. For prophylaxis, a target antifactor Xa range of $0.1-0.4 \mathrm{U} / \mathrm{ml}$ was used. Antifactor Xa levels were measured at 4 hours after the second or third dose, then weekly for the duration of treatment, per institutional protocol. In the event of bleeding or decreased renal function, antifactor Xa levels were measured more frequently.

One course of therapy was defined as daily administration of enoxaparin for a specific indication. Patients in whom therapy was briefly interrupted to perform invasive procedures were included.

\section{Demographic Information}

Weight, sex, age at diagnosis, and associated medical and surgical comorbidities were recorded for all patients. Likewise, data on treatment, such as duration of therapy, maintenance dosage, and dosing schedule, were recorded, and plasma antifactor Xa activity was noted.

Efficacy of LMWH therapy was assessed clinically in all patients. Efficacy was determined by the absence of symptomatic clot extension or recurrence in patients receiving therapeutic doses of enoxaparin and by the absence of symptomatic new clot formation in patients receiving prophylactic doses of enoxaparin. Major and minor bleeding complications were noted. Bleeding complications were considered major if a blood transfusion or surgical intervention was required to treat clinical bleeding, or if anticoagulant therapy was stopped because the responsible physician assessed the bleeding to be excessive. All cases of bleeding in the CNS and retroperitoneal space were classified as major hemorrhages. All other hemorrhages were classified as minor.

\section{Results}

\section{Patient Population}

There were 41 patients in the pediatric age group (less than 18 years of age) who received enoxaparin during the 
TABLE 2. Children receiving therapeutic LMWH

\begin{tabular}{|c|c|c|c|c|c|}
\hline $\begin{array}{l}\text { Sex/Age } \\
\text { (yrs) }\end{array}$ & Condition & Operation & Indication & $\begin{array}{l}\text { Other Bleeding } \\
\text { Risk }\end{array}$ & $\begin{array}{l}\text { Type of Major } \\
\text { Hemorrhage }\end{array}$ \\
\hline$M / 3$ & Thoracic epidural abscess & T2-3, T-6, \& T-12, laminectomies & DVT & & \\
\hline $\mathrm{F} / 5$ & Cranial epidural abscess & Craniotomy, evacuation abscess & CVST & Thrombocytopenia & Palatal \\
\hline $\mathrm{M} / 0.2$ & Yolk sac tumor & Craniotomy, tumor resection & DVT & & \\
\hline $\mathrm{F} / 2$ & $\begin{array}{l}\text { Ventriculoperitoneal shunt infec- } \\
\text { tion }\end{array}$ & Craniotomy, evacuation abscess & DVT & & \\
\hline$M / 1$ & Moyamoya disease & Craniotomy, indirect revascularization & Arterial thrombosis & Aspirin & Intracerebral \\
\hline $\mathrm{M} / 16$ & Lumbar epidural abscess & $\begin{array}{l}\text { L1-3 laminectomies, evacuation } \\
\text { abscess }\end{array}$ & DVT & & \\
\hline $\mathrm{F} / 10$ & Moyamoya disease & Craniotomy, indirect revascularization & Ischemic stroke & Aspirin & \\
\hline$M / 3$ & Tuberculous meningitis & Ventriculoperitoneal shunt & CVST & Aspirin & Upper GI \\
\hline$M / 1$ & Sickle cell w/ moyamoya disease & Indirect revascularization procedure & DVT & Aspirin & \\
\hline$M / 9$ & Obstructive hydrocephalus & Endoscopic third ventriculostomy & DVT & & \\
\hline $\mathrm{M} / 1$ & Closed traumatic brain injury & Cranioplasty \& EVD & DVT & & \\
\hline $\mathrm{M} / 0.3$ & $\begin{array}{l}\text { Suprasellar pilomyxoid astrocy- } \\
\text { toma }\end{array}$ & Craniotomy for tumor & CVST & & \\
\hline $\mathrm{M} / 0.3$ & $\begin{array}{l}\text { X-linked chronic granulomatous } \\
\text { disease }\end{array}$ & Craniotomy, resection of dural lesion & DVT & & \\
\hline $\mathrm{F} / 17$ & Cerebral sinus thrombosis & Camino ICP monitor & CVST & & \\
\hline $\mathrm{M} / 17$ & Lumbar decubitus ulcer & Vascularized wound flap & DVT & & \\
\hline $\mathrm{F} / 11$ & Shunt infection & Ventriculoatrial shunt & DVT & & \\
\hline$M / 3$ & Atypical teratoid rhabdoid tumor & Ventriculoperitoneal shunt & DVT & & \\
\hline
\end{tabular}

CVST = cerebral venous sinus thrombosis; DVT = deep venous thrombosis; EVD = external ventricular drain; GI = gastrointestinal; ICP = intracranial pressure.

study period. Of these patients, 17 received LMWH for management of VTEs, and 24 received LMWH for prophylaxis.

\section{Demographic Information}

The ages of children who received therapeutic doses ranged from 2 months to 17 years (median 3 years, mean 6 years). The chronological age of 4 patients (about 25\%) was less than 1 year at the time of treatment initiation. The male/female ratio was $2: 1$.

The ages of children who received prophylactic doses ranged from 3 years to 18 years (median 15 years, mean age 14 years). The chronological age of all of these patients was older than 1 year at the time of treatment initiation. The male/female ratio was 3:2.

\section{Comorbidities}

An underlying coagulopathy or secondary anticoagulant medication administration was noted in $29 \%$ of patients receiving therapeutic doses and in $8 \%$ of patients receiving prophylactic doses of LMWH (Tables 1 and 2). LMWH was dispensed for the treatment of VTEs for reasons including venous sinus thrombosis, arterial thrombosis, deep venous thrombosis, and ischemic stroke (Table 3).

LMWH was dispensed for the prevention of VTEs in 24 patients. General indications for prophylactic anticoagulation were expected altered mobility for more than 48 hours in an older child (age less than 12 years or weight more than $65 \mathrm{~kg}$ ) (Fig. 1). Specific indications included general recovery after spine procedures with or without fusion $(n=11)$, spinal cord injury $(n=3)$, weakness after craniotomy $(n=5)$, bed rest for spinal fluid leak $(n=1)$, and traumatic brain injury $(\mathrm{n}=3)$. Two younger patients who did not meet the indications based on age, weight, and mobility status received prophylactic anticoagulation for high-risk factors due to history of ischemic strokes related to protein $\mathrm{C}$ deficiency.

\section{Treatment}

Table 4 lists the doses observed to achieve target antifactor Xa levels and the range of maintenance doses required. Conversion to warfarin was performed in 2 of 17 (12\%) children receiving LMWH treatment, due to intolerance of daily needle injections.

Aspirin was used as an additional part of the anticoagu-

TABLE 3. Types of thrombotic disease in patients receiving therapeutic LMWH

\begin{tabular}{lc}
\hline \multicolumn{1}{c}{ Disease Type } & No. of Patients \\
\hline Overall no. & 17 \\
\hline DVT/PE & 11 \\
\hline Stroke & 1 \\
\hline Dural sinus thrombosis & 4 \\
\hline Arterial thrombosis & 1 \\
\hline
\end{tabular}

$\mathrm{PE}=$ pulmonary embolus. 

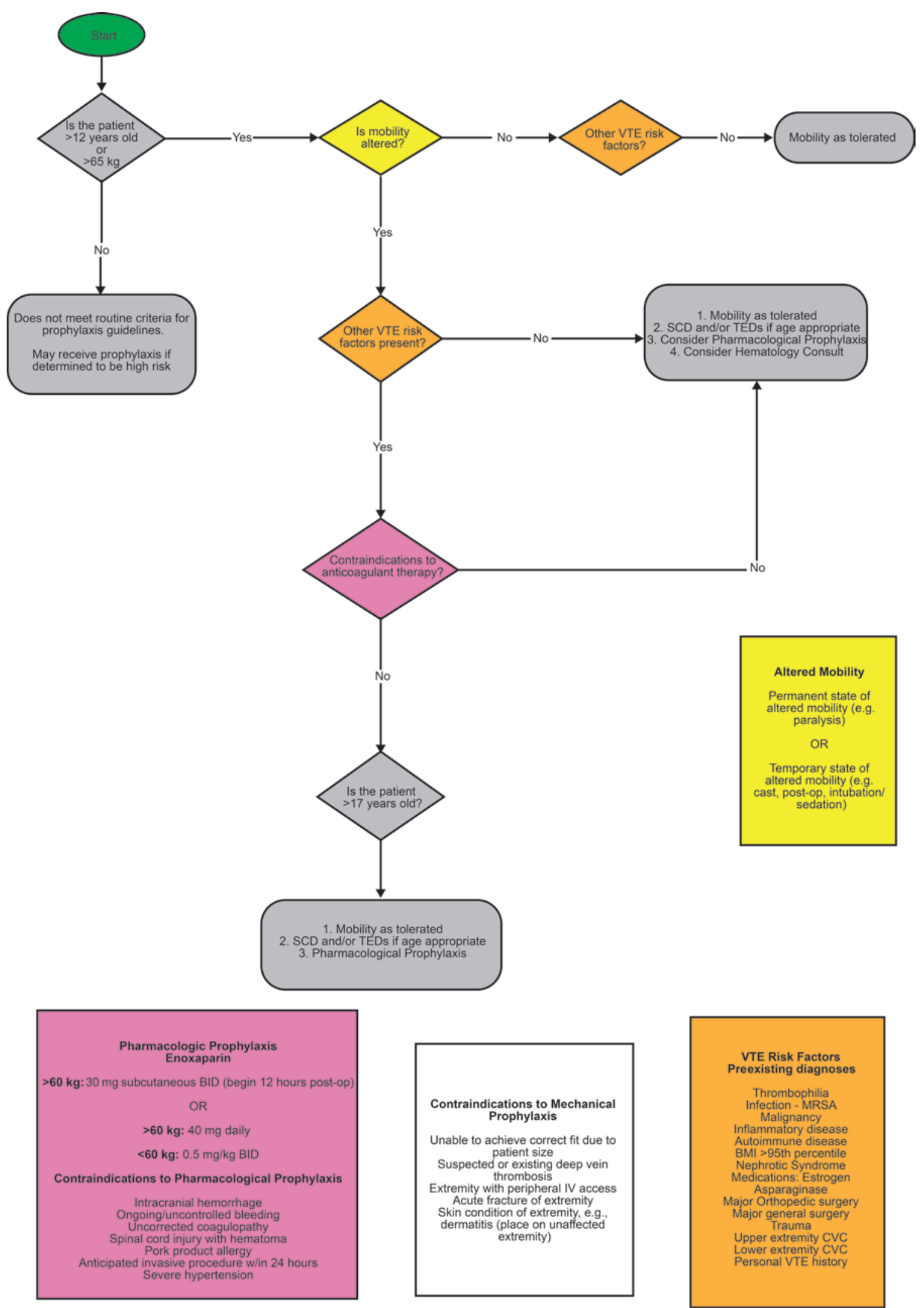

FIG. 1. Our institutional guidelines for VTE risk assessment and prophylaxis against VTE in children. BID = twice daily; BMI = body mass index; CVC = central venous catheter; IV = intravenous; MRSA = methicillin-resistant Staphylococcus aureus; post-op = postoperative; $\mathrm{SCD}=$ sequential compression device; $\mathrm{TED}=$ thromboembolism-deterrent hose. Figure is available in color online only. 
lation regimen in 4 of 17 children (24\%) receiving LMWH treatment and in $1(4 \%)$ receiving prophylaxis.

In the group receiving therapeutic doses, only 2 of the 17 children (12\%) received LMWH for 20 days or less. The reasons for discontinuation of LMWH were as follows: conversion to warfarin $(n=2)$, resolution of clot or completion of therapy $(n=14)$, and major bleeding $(n=1)$. LMWH was briefly withheld but then reinitiated within 48 hours in both patients who had minor bleeding episodes.

In the group receiving prophylactic doses, 16 of the 24 patients $(67 \%)$ received LMWH for 7 days or less. Three patients (13\%) received indefinite continuation of the therapy for permanent impaired mobility. The reasons for discontinuation of LMWH were as follows: placement of an inferior vena cava filter $(\mathrm{n}=1)$, major bleeding $(\mathrm{n}=1)$, and mobilization of the patient $(n=20)$.

Twenty-one children $(51 \%)$ received enoxaparin for therapy or prophylaxis only while being treated as hospital inpatients, and 20 (49\%) received continued enoxaparin therapy in an outpatient setting.

\section{Outcome}

The efficacy of LMWH was assessed clinically in all patients, with patients who had symptoms of new or recurrent thrombosis undergoing objective radiographic testing. Documented progression of thrombosis occurred in none of the patients while receiving therapeutic LMWH, nor was there any symptomatic recurrence or incidence of new VTEs in those patients receiving prophylactic LMWH.

\section{Complications}

None of the patients in this study died while receiving LMWH. There were no correlations between duration of treatment, dosage schedule, or drug levels with the development of complications. Major bleeding occurred in 1 patient $(6 \%)$ receiving therapeutic doses of enoxaparin, and minor bleeding occurred in another $2(12 \%)$. The major bleeding consisted of an intracerebral parenchymal hemorrhage requiring surgical evacuation. All major or minor bleeding complications occurred in patients with coexisting coagulopathies (i.e., severe thrombocytopenia, aspirin use).

There was only 1 major bleeding complication (4\%) that occurred among the 24 patients who received prophylactic LMWH. This was an intracerebral hemorrhage in a child who had previously unrecognized hemophilia.

\section{Discussion}

The advantages of LMWHs in adults have resulted in its increased off-label use in pediatric patients. ${ }^{4}$ Few studies describe the pharmacokinetics or use of LMWH in children,,$^{3,10,21}$ and no studies in the literature evaluate the safety and efficacy of LMWHs in the management of VTEs in pediatric neurosurgical patients. ${ }^{11}$ Concerns regarding the use of unfractionated heparin followed by oral anticoagulants and the advantages of LMWH have resulted in growing interest in the use of LMWHs as alternative therapy in children. ${ }^{10}$
TABLE 4. Treatment characteristics for patients receiving LMWH

\begin{tabular}{cc}
\hline Dose $(\mathrm{mg} / \mathrm{kg} / \mathrm{d})$ & No. of Patients \\
\hline Prophylactic & \\
\hline 0.25 & 4 \\
0.5 & 6 \\
\hline 0.75 & 3 \\
\hline 1 & 11 \\
\hline Therapeutic & 1 \\
\hline 1.5 & 12 \\
\hline 2 & 3 \\
\hline 3 & 1 \\
\hline 3.5 &
\end{tabular}

Patients in our study had characteristics similar to children described in other studies who had or were at risk for VTEs. ${ }^{2,10,15,18,21}$ There was a predominance of adolescents relative to younger children, ${ }^{21}$ and most children with VTEs had serious comorbidities, such as moyamoya disease or intracranial infections. Based on the higher rates of VTEs documented in adults, concern exists that the onset of puberty places adolescents at higher risk for VTEs than younger children. ${ }^{21}$ The heterogeneity and complexity of medical problems in our patients with VTEs reflect the current status of pediatric tertiary care hospitals. ${ }^{10}$ In contrast to children with deep venous thrombosis/pulmonary embolus, most children with arterial and venous thrombosis in the CNS were previously healthy. ${ }^{7,9,10}$

In our study, there was considerable variation in the maintenance dose requirements for prophylaxis. Prophylactic dosing requirements were about $25 \%-30 \%$ of the therapeutic doses to achieve the target antifactor Xa range. There is a growing body of literature suggesting that an increased enoxaparin dosage in pediatric patients, particularly young patients, is required. ${ }^{1}$ In a study by Punzalan et al., ${ }^{17}$ the once-daily dosing is appealing for prophylaxis; however, the peak antifactor Xa level is in the therapeutic range, which may predispose children to an increased risk of bleeding when prophylaxis is the aim. ${ }^{12}$ The safety and efficacy of twice-daily versus once-daily dosing for prophylaxis can only be assessed in a randomized clinical trial with clinical outcomes. ${ }^{12}$

The efficacy of LMWH was assessed by determining either if it prevented new or recurrent VTEs in patients with previous VTEs or if it prevented VTEs in patients at risk. Patients with symptoms of thrombosis underwent radiographic workup. Given the heterogeneity of this study cohort, both in terms of indications for anticoagulation and the duration and dosage of anticoagulation, routine radiographic assessment was not performed, which is consistent with standard pediatric and adult practice. ${ }^{10}$ No new or progressive VTEs occurred in children receiving prophylactic LMWH. These rates of new VTEs are similar to results from other clinical series involving children. ${ }^{10}$

Significant symptomatic bleeding occurred in 4 patients (about 10\%). Three of these patients were receiving therapeutic doses of $\mathrm{LMWH}$, and 1 was receiving prophylactic doses. The rate of major bleeding in our study was 
similar to the rate of major bleeding in adult patients ${ }^{22}$ and children receiving unfractionated heparin. ${ }^{14}$

\section{Conclusions}

VTEs are underappreciated in the pediatric age group. LMWH represents an important advance. It offers a safe and effective form of anticoagulation in pediatric neurosurgical patients with or at risk for VTEs and, therefore, should be routinely used prophylactically or therapeutically in the at-risk pediatric patient population. However, caution should be applied to patients with preexisting bleeding disorders and those concurrently receiving antiplatelet agents, as major bleeding complications were shown in this subset of patients in our series.

All pediatric patients undergoing enoxaparin therapy should be monitored using antifactor Xa test measurement, as guidelines describe. ${ }^{3}$ An initial higher enoxaparin dose may be necessary to achieve target anticoagulation, particularly in young children. Further study is warranted in a randomized controlled fashion to compare LMWH with unfractionated heparin and oral anticoagulants in the treatment and prevention of VTEs in children in a pediatric neurosurgical service.

\section{References}

1. Andrade-Campos MM, Montes-Limón AE, Fernandez-Mosteirin N, Salvador-Osuna C, Torres M, Lucia-Cuesta JF, et al: Dosing and monitoring of enoxaparin therapy in children: experience in a tertiary care hospital. Blood Coagul Fibrinolysis 24:194-198, 2013

2. Andrew M, David M, Adams M, Ali K, Anderson R, Barnard $\mathrm{D}$, et al: Venous thromboembolic complications (VTE) in children: first analyses of the Canadian Registry of VTE. Blood 83:1251-1257, 1994

3. Andrew M, Michelson AD, Bovill E, Leaker M, Massicotte MP: Guidelines for antithrombotic therapy in pediatric patients. J Pediatr 132:575-588, 1998

4. Askegard-Giesmann JR, O'Brien SH, Wang W, Kenney BD: Increased use of enoxaparin in pediatric trauma patients. J Pediatr Surg 47:980-983, 2012

5. Barnard DR, Hathaway WE: Neonatal thrombosis. Am J Pediatr Hematol Oncol 1:235-244, 1979

6. Barnard DR, Simmons MA, Hathaway WE: Coagulation studies in extremely premature infants. Pediatr Res 13:1330-1335, 1979

7. Bosworth T, deVeber G: From major findings, a clearer picture of childhood stroke. Neurol Rev 6:36, 1998

8. Candrilli SD, Balkrishnan R, O'Brien SH: Effect of injury severity on the incidence and utilization-related outcomes of venous thromboembolism in pediatric trauma inpatients. Pediatr Crit Care Med 10:554-557, 2009

9. deVeber G, Adams M, Andrew M: Canadian pediatric ische- mic stroke registry (analysis III). Can J Neurol Sci 22:S21S24, 1995

10. Dix D, Andrew M, Marzinotto V, Charpentier K, Bridge S, Monagle P, et al: The use of low molecular weight heparin in pediatric patients: a prospective cohort study. J Pediatr 136:439-445, 2000

11. Levy ML, Granville RC, Hart D, Meltzer H: Deep venous thrombosis in children and adolescents. J Neurosurg 101 (1 Suppl):32-37, 2004

12. Massicotte MP: Low-molecular-weight heparin therapy in children. J Pediatr Hematol Oncol 22:98-99, 2000

13. Massicotte MP: Low-molecular-weight heparin therapy in children. J Pediatr Hematol Oncol 23:189-194, 2001

14. Massicotte P, Adams M, Marzinotto V, Brooker LA, Andrew M: Low-molecular-weight heparin in pediatric patients with thrombotic disease: a dose finding study. J Pediatr 128:313318, 1996

15. Nowak-Göttl U, von Kries R, Göbel U: Neonatal symptomatic thromboembolism in Germany: two year survey. Arch Dis Child Fetal Neonatal Ed 76:F163-F167, 1997

16. O'Neill JA Jr, Neblett WW III, Born ML: Management of major thromboembolic complications of umbilical artery catheters. J Pediatr Surg 16:972-978, 1981

17. Punzalan RC, Hillery CA, Montgomery RR, Scott CA, Gill JC: Low-molecular-weight heparin in thrombotic disease in children and adolescents. J Pediatr Hematol Oncol 22:137142,2000

18. Schmidt B, Andrew M: Neonatal thrombosis: report of a prospective Canadian and international registry. Pediatrics 96:939-943, 1995

19. Schmidt B, Andrew M: Neonatal thrombotic disease: prevention, diagnosis, and treatment. J Pediatr 113:407-410, 1988

20. Schmidt B, Zipursky A: Thrombotic disease in newborn infants. Clin Perinatol 11:461-488, 1984

21. Thompson AJ, McSwain SD, Webb SA, Stroud MA, Streck CJ: Venous thromboembolism prophylaxis in the pediatric trauma population. J Pediatr Surg 48:1413-1421, 2013

22. Weitz JI: Low-molecular-weight heparins. N Engl J Med 337:688-698, 1997

\begin{abstract}
Author Contributions
Conception and design: Jea, Gonda. Acquisition of data: Jea, Gonda, Fridley, Ryan, Briceño, Lam. Analysis and interpretation of data: Jea, Gonda, Fridley, Ryan, Briceño, Lam. Drafting the article: Jea, Gonda. Critically revising the article: all authors. Reviewed submitted version of manuscript: all authors. Approved the final version of the manuscript on behalf of all authors: Jea. Administrative/technical/material support: Luerssen. Study supervision: Luerssen.
\end{abstract}

\section{Correspondence}

Andrew Jea, Texas Children's Hospital, 6621 Fannin St., CCC 1230.01, 12th Fl., Houston, TX 77030. email: ahjea@ texaschildrens.org. 